\title{
VARIAÇÃO LINGUÍSTICA E ENSINO: CONCEITOS E (IM)POSSIBILIDADES
}

\author{
VIVIANE DE ANDRADE SOARES SENA (UFOP) ${ }^{1}$ \\ SOELIS TEIXEIRA DO PRADO MENDES (UFOP) ${ }^{2}$
}

\begin{abstract}
RESUMO: Por meio deste artigo pretendemos discutir achados da pesquisa intitulada "Esta língua vareia: uma análise da variação linguística no ensino de língua portuguesa em Mariana, MG"3 (Soares-Sena, 2018), a partir da qual e sob a perspectiva da Sociolinguística Variacionista Laboviana (2008 [1972]) apresentamos uma análise a respeito do tratamento dado à variação linguística nos ensinos Fundamental II e Médio. Assim, visando desenvolver ainda mais o tema em questão, acrescentamos a esta discussão algumas reflexões acerca da variação linguística no processo de alfabetização-letramento de crianças; conhecimento que nos foi possibilitado trazer a este estudo a partir da realização da disciplina "LIG948 - STV em Linguística Aplicada: Da aquisição da fala à apropriação da escrita pela criança" do Programa de Pós Graduação em Estudos Linguísticos da Universidade Federal de Minas Gerais. Dessa maneira, evidenciaremos resultados da pesquisa empírica e refletiremos, ainda, sobre o processo de alfabetização no Ensino Fundamental I (anos iniciais $-1^{\circ}$ ao $5^{\circ}$ ano). Isso para que possamos discutir conceitos $\mathrm{e}$ (im)possibilidades ao ensino-aprendizagem de Língua Portuguesa na educação básica como um todo. Os resultados nos mostram que poderemos compreender que, embora existam grandes estudos com foco em um ensino-aprendizagem diverso, criativo, dinâmico, efetivo e significativo com tendências à erradicação do analfabetismo no Brasil (Soares, 2002, 2018; Faraco, 1992, 2008, 2016; Bortoni-Ricardo, 2005; dentre outros), ainda há muitas lacunas no nosso ensino. Da alfabetização ao ensino médio, existe um caminho extenso a ser percorrido para se alcançar a educação de qualidade.
\end{abstract}

PALAVRAS-CHAVE: Língua portuguesa. Prática de ensino. Variação linguística. Alfabetizaçãoletramento. Consciência fonológica.

\begin{abstract}
In this article, we aim to discuss the findings of the research entitled "This language veries: an analysis of the linguistic variation in Portuguese language teaching in Mariana, Minas Gerais, Brazil" (SOARES-SENA, 2018). From the perspective of the Labovian Variationist Sociolinguistics (2008 [1972]), we hereby present an analysis of the treatment given to linguistic variation in Elementary and High School. Thus, as a means of further developing the theme in question, we have added to this discussion some reflections about linguistic variation in children's literacy process. Such knowledge was possible to be incorporated into this study after attending the classes held in the course "LIG948 - VTS* in Applied Linguistics: From speech acquisition to the appropriation of writing by the child" within the scope of the Graduate Program in Linguistic Studies at the Federal University of Minas Gerais. In doing so, we will evince the results of the empirical research and also reflect on the literacy process in Elementary School (early years - 1st to 5th year). Hence we can discuss concepts and (im) possibilities for the teaching and learning of Portuguese in basic education as a whole. The results show us that, although there are broad studies focusing on a diverse, creative, dynamic, effective and significant teaching-learning trend with a tendency to eradicate illiteracy in Brazil (Faraco, 1992, 2008, 2016; Soares, 2002, 2018;; Bortoni-Ricardo, 2005; among others), there are still several gaps in our teaching. From the literacy stage to high school, much remains to be done in order to achieve quality education.
\end{abstract}

KEYWORDS: Portuguese language. Teaching practice. Linguistic variation. Literacy. Phonological awareness.

\footnotetext{
1 Mestra em Letras: Estudos da Linguagem pela Universidade Federal de Ouro Preto, viviannevas@hotmail.com.

2 Professora Associada do Departamento de Letras da Universidade Federal de Ouro Preto, soelisufop@gmail.com.

${ }^{3}$ Dissertação de mestrado.
} 


\section{$=$ TRAMA $=$}

\section{INTRODUÇÃO}

Neste artigo discutiremos, primeiramente, sobre variação linguística e ensinoaprendizagem de língua portuguesa (LP) nos anos finais do ensino fundamental e no ensino médio na educação pública e particular no Município de Mariana, Minas Gerais. O que vai nos servir como respaldo a essa discussão serão, fundamentalmente, alguns achados da pesquisa de dissertação intitulada "Esta língua vareia: uma análise da variação linguística no ensino de língua portuguesa em Mariana, MG" (Soares-Sena, 2018). Esse referido trabalho foi realizado com o apoio da Coordenação de Aperfeiçoamento de Pessoal de Nível Superior - Brasil (CAPES) - Código de Financiamento 001.

Além disso, interessa-nos pensar o ensino anterior ao que foi observado na supramencionada pesquisa, isto é, é preciso compreender como se inicia esse processo no que tangem os anos iniciais do ensino fundamental; ou seja, nosso interesse, com isso, é discutir também variação linguística na alfabetização de crianças. Para isso, uma vez que não nos foi, ainda, possível uma observação nesse campo, iremos nos pautar, principalmente, no referencial teórico e nas discussões estabelecidas na disciplina "LIG948 - STV em Linguística Aplicada: Da aquisição da fala à apropriação da escrita pela criança" do Programa de Pós Graduação em Estudos Linguísticos da Universidade Federal de Minas Gerais (PosLin/UFMG), a qual cursamos como discente de disciplina isolada, em 2019. As contribuições da "LIG948" nos servirão como embasamento à construção deste artigo. Sendo assim, mesmo que não tenhamos tido ainda a possibilidade da pesquisa empírica no nível da alfabetização, nos anos iniciais de aprendizagem escolar, pretendemos que este trabalho contribua para essa discussão no futuro.

Uma vez que iremos falar de ensino-aprendizagem formal de Língua Portuguesa (LP), precisamos entender a importância da escola na vida das crianças e dos jovens inseridos nesse espaço. A escola é um dos mais importantes e decisivos campos de prática e de interação social desses sujeitos. Quando pensamos nas crianças "pequenininhas", principalmente, podemos, talvez, afirmar que a escola seja o seu segundo maior espaço de interação. Por isso, esse campo de formação precisa ser um meio de ensino-aprendizagem que faz a diferença na vida de todos. Para que assim o seja, a escola deve tratar da diversidade como um todo, mas aqui consideraremos a diversidade linguística. Esse processo de ensino que considera o diverso, para além de ensinar o conteúdo, educa para o bem, para o respeito, para a solidariedade. Assim sendo, todo sujeito, desde a sua infância, faria uso competente e consciente da linguagem, independentemente de sua classe, raça ou cultura, porque a todos seria possibilitado o saber letrado, que é função da escola propiciar.

Ao pensarmos a escola como um espaço de interação e como um mecanismo para a transformação social, consequentemente, deveríamos ter um ensino que considerasse o aluno como quem pertence a ao menos um grupo social anterior à sala de aula, que não seria o único, não seria o primeiro e, certamente, não seria o último grupo a que esse aluno estaria inserido. Nesse sentido é importante discutirmos o ensino de LP, uma vez que a forma como acontece o trabalho com linguagem, em todos os níveis do ensino básico, pode possibilitar uma menor ou maior participação do sujeito nas diversas esferas sociais, impactando diretamente na sua autonomia.

Por isso pretendemos elucidar, a partir da atuação de professores de Língua Portuguesa do Ensino Fundamental II e do Ensino Médio, de que maneira algumas escolas vêm legitimando determinados saberes e deslegitimando outros e como isso afeta os alunos.

À vista disso, como acreditamos que alguns problemas de linguagem apresentados por alunos em fase de conclusão da educação básica possuem raízes na fase da Revista Trama | Volume 16 | Número 37 | Ano 2020 | p. 84-99 | e-ISSN 1981-4674 


\section{$=$ TRAMA $=$}

alfabetização, teceremos considerações sobre o processo de aquisição da língua escrita pela criança, abordando questões sobre diferentes facetas que envolvem o fenômeno alfabetização (SOARES, 2018). O ponto principal a nortear esta discussão é a variação linguística. A criança, obviamente, chega à escola dominando no mínimo uma variedade da língua, mas como o professor lida com esse fato?

\section{METODOLOGIA}

Para realizarmos a supramencionada pesquisa de mestrado, fizemos investigação por meio de estudo de caso, que teve como proposta discutir o tratamento da variação linguística no ensino de Língua Portuguesa, considerando a abordagem desse tema na prática de 4 professoras de redes públicas e privada de ensino, em 2017.

Conforme Lüdke e André (1986), o estudo de caso é uma estratégia de investigação por meio da qual se realiza o estudo de um caso simples e específico ou complexo e abstrato, precisa ser sempre bem delimitado, contextualizado em tempo e lugar para que seja possível a realização de uma busca minuciosa de informações. Esse modo de investigação focaliza a realidade de maneira contextualizada, isto é, permite estudar o caso (objeto) no seu contexto de vida real, utilizando fontes de evidência diversas (qualitativas e quantitativas).

Segundo Yin (2005), o estudo de caso representa uma investigação empírica e compreende um método abrangente, incluindo planejamento, coleta e análise de dados. Dessa forma, a discussão permite determinar os caminhos seguidos, avaliar como se desenvolveu o caso, apresentar a razão para estudá-lo e, por fim, fazer a conclusão, identificando o que se aprendeu a partir do caso estudado. Portanto, de acordo com Gil (1995), o estudo de caso não se trata de um roteiro rígido, mas o seu delineamento pode ser definido em quatro fases, sendo elas: a delimitação da unidade-caso; a coleta de dados; a seleção, análise e interpretação dos dados; e a elaboração do texto.

Nesse sentido realizamos observações em três escolas na cidade de Mariana ${ }^{4}$, sendo elas duas escolas públicas da rede estadual de ensino e uma escola particular; acompanhamos às aulas, especificamente em quatro turmas: um nono ano do Ensino Fundamental da Rede Estadual de Ensino; um nono ano do Ensino Fundamental de uma Escola Particular; um terceiro ano do Ensino Médio de uma Escola Pública da Rede Estadual; um terceiro ano do Ensino Médio de uma Escola Particular. Isso aconteceu no período de fevereiro de 2017 a julho de 2017. Nesse tempo, aproximadamente cinco meses, foi-nos possível observar e registrar 72 aulas: 18 aulas em cada uma das mencionadas turmas.

Além da observação de aulas de Língua Portuguesa no Ensino Fundamental e no Ensino Médio, analisamos também Planejamentos de Aulas das professoras cujas aulas observamos. Isso porque acreditamos que o número de aulas a que acompanhamos não garantiria que, naquele período, as professoras dessas quatro turmas tratariam da variação. $\mathrm{E}$, por se tratar de uma pesquisa de mestrado, não haveria espaço para um estudo longitudinal. Por conseguinte, realizarmos uma análise descritiva e comparativa desses documentos, enquanto discursos das escolas/professores, com as aulas a que acompanhamos. A nossa compreensão foi a de que, caso o tema não fosse abordado durante as aulas observadas, poderíamos analisar se haveria a intenção de que ele fosse discutido em algum outro momento ao longo do ano.

\footnotetext{
${ }^{4}$ O projeto da mencionada pesquisa foi submetido ao Comitê de Ética em Pesquisa, cujo parecer foi favorável ao seu desenvolvimento e possui número 2.332.106. A fim de mantermos o sigilo necessário quanto aos campos e participantes da pesquisa, não revelaremos os espaços e as pessoas envolvidas.
} Revista Trama | Volume 16 | Número 37 | Ano 2020 | p. 84-99 | e-ISSN 1981-4674 


\section{$=$ TRAMA $=$}

A nossa investigação partiu da hipótese de que a escola não concede um tratamento adequado ao uso das variedades desprestigiadas da língua pelos alunos. E, conforme as orientações dos documentos que regulamentam o ensino "Parâmetros Curriculares Nacionais" e "Currículo Básico Comum" (PCN; CBC), escola e professores devem compreender que existem variações na língua e que as variedades linguísticas têm valor social discrepante.

Dentre os questionamentos norteadores da pesquisa, no que tange à teoria, destacamos estes: o trabalho com variação se encontra inserido no Planejamento de Aula do Professor? Com relação à prática: em sua atuação pedagógica, o professor aborda esse fato inerente à língua que ele ensina? $\mathrm{E}$, se o faz, como o faz? Como o professor reage frente às manifestações da variação linguística presentes na fala e na escrita dos alunos? Há aceitação/compreensão ou omissão? E acreditamos desde o início que, se vigorasse a omissão, resultante do silenciamento ${ }^{5}$, a interpretação não nos seria negada, pois o silêncio também é uma forma de resposta, já que, como nos diz Orlandi (2007), "há um modo de estar em silêncio que corresponde a um modo de estar no sentido" (p. 11).

A fim de enriquecer este estudo, que pretende evidenciar algumas discussões e resultados alcançados com a referida pesquisa de mestrado, acrescentaremos questões concernentes à variação linguística no processo de alfabetização e letramento nos anos iniciais da educação básica. Faremos isso embasando-nos pelo conhecimento produzido durante o período de realização da disciplina já citada na seção de introdução: "LIG948" cuja finalidade foi a de possibilitar que construíssemos uma compreensão sobre o processo da "aquisição da fala à apropriação da escrita pela criança".

Sendo assim, no que se refere à discussão concernente ao processo alfabetizaçãoletramento (anos iniciais do ensino fundamental), os caminhos metodológicos a que seguimos, como embasamento a este trabalho, foram a realização da mencionada disciplina de PósGraduação e a revisão de literatura das principais teorias/autores estudados nesse curso, principalmente Soares (2018).

Em todos os casos, o nosso foco será em abordar essencialmente conceitos ligados à variação e ensino, no tocante à forma como a omissão ou o "não tratamento" da diversidade linguística influencia na aprendizagem da variedade formal da língua e contribui para a legitimação do conhecimento de alguns sujeitos e também corrobora o silenciamento de outros sujeitos.

\section{TEORIA DA VARIAÇÃO LINGUÍSTICA ABORDAGEM TEÓRICA}

O que é, afinal, "variação linguística"? Para responder a essa questão, primeiramente, iremos conceituar o que consideramos por língua, linguagem e comunidade linguística e, depois, falaremos da variação e de seu tratamento no ensino formal de língua. Tudo isso será feito considerando o viés da Sociolinguística Variacionista. Mais especificamente, consideraremos a Sociolinguística Educacional, levando-se em conta, principalmente, Labov (2008, [1972]), Soares (2002, 2018); Bortoni-Ricardo (2005); Faraco (2008).

\footnotetext{
5 "O silêncio não fala. O silêncio é. Ele significa." (ORLANDI, 1997, p. 33). Nessa obra, Orlandi (1997) fala sobre as formas do silêncio, mostrando que o silêncio da ordem do "não dito" é aquele cujo sentido ou resposta se dá pelo silenciamento do discurso (não há fala, não há escrita) e, para a autora, o não dito produz muito sentido.
} 


\section{$=$ TRAMA $=$}

Segundo Labov (2008, 1972), principal representante da teoria da variação linguística, a língua é heterogênea por natureza, e isso se deve aos fatores sociais que a influenciam. Assim, a língua não pode ser considerada de forma isolada da sociedade. Nessa perspectiva de Labov (2008, [1972]), a língua é mais do que um veículo transmissor de informação, ela possui também a função de estabelecer contatos sociais, ou seja, existe uma íntima relação entre língua e sociedade. Mesmo a língua enquanto sistema evolui concomitante à sociedade, refletindo, de certa maneira, "padrões de comportamento, que variam em função do tempo e do espaço". Portanto, a língua é dinâmica, diversa e social.

Labov (2008, [1972]) se mostra resistente à necessidade de haver um ramo da linguística específico para estudar a língua em sociedade: a sociolinguística "nasceu" na segunda metade do século XX. Para Labov não poderia existir qualquer teoria com foco nos estudos sobre a linguagem que não considerasse a língua como um fato social. Por isso, o autor afirma que, por vários anos, resistiu ao termo sociolinguística, "já que ele implica que pode haver uma teoria ou prática linguística bem-sucedida que não seja social" (LABOV, 2008 [1972], p. 13). Para ele, a própria linguística deveria ser o suficiente.

Bagno (2017, p. 227) considera o estruturalismo clássico e o gerativismo, "com seu 'falante ideal', que não vive em nenhum lugar do planeta", como um "escândalo epistemológico" para todos que entendem ser impossível cortar a língua do falante real, ou seja, do social, do político e da história, para analisá-la em um laboratório "como um pedaço de carne morta". A esse "escândalo" é que Bagno (2017) atribui a necessidade da sociolinguística, para ele, o conceito de língua não é algo simples de se definir. No entanto, falaremos da língua como um elemento histórico, social, político, cultural, com "vínculo estreito com a identidade individual, comunitária e nacional” (BAGNO, 2017, p. 224).

Nesse sentido, (um)a língua é o seu uso, e isso não significa deixar de considerar suas teorizações, mas, sim, de delinear a necessidade de acrescentar-lhes, além do "sistêmico", do "estrutural", também e, com igual valor, o sociocultural, o sociocognitivo e o político ideológico, conforme explicita Bagno (2017). Temos, pois, que a língua naturalmente humana apresenta variabilidade linguística, isto é, há "formas distintas que, em princípio, se equivalem" nos diferentes níveis linguísticos (vocabulário, sintaxe, fonético, fonológico etc.) (MOLLICA, 2003, p. 9).

Desse modo, torna-se valioso destacar a linguagem nesse cenário, cuja noção, igualmente à de língua, segundo Bagno (2017), possui muitos sentidos e significados. No entanto, iremos nos ater à noção de linguagem enquanto "todo e qualquer sistema de signos empregados pelos seres humanos na produção de sentido, isto é, para expressar sua faculdade de representação da experiência/conhecimento" (BAGNO, 2017, p. 230). É dessa concepção de linguagem que podemos perceber e distinguir a linguagem verbal e a linguagem não verbal.

A linguagem verbal é aquela com que podemos nos expressar por meio do verbo, ou seja, usando as palavras de uma dada língua, sendo essa língua "o sistema de signos mais completo, complexo, flexível e adaptável de todos" (BAGNO, 2017, p. 230-231). Assim, "não por acaso, é de língua que deriva a palavra linguagem, pois toda linguagem é sempre uma 'imitação da língua', uma tentativa de produção de sentido tão eficiente quanto a que se realiza por meio da língua" (FARACO, 2016, p. 231); a linguagem verbal pode ser escrita, oral ou sinalizada.

A linguagem não verbal não se vale de signos linguísticos, a ela correspondem todos os outros signos de diferentes naturezas, como por exemplo, as imagens em um outdoor, a sinalização de trânsito, determinados sons - como o apito de trânsito ou de juiz de futebol enfim, tudo o que passa alguma informação, que faz sentido, que é comunicação, mas não é Revista Trama | Volume 16 | Número 37 | Ano 2020 | p. 84-99 | e-ISSN 1981-4674 


\section{$=$ TRAMA $=$}

verbal. Isso é o que possibilita que se fale em linguagem de programação de computador, linguagem corporal, linguagem fotográfica e infinitas representações/expressões da linguagem que não acontecem na forma verbal.

De acordo com Labov (2008 [1972]) é por meio da linguagem, competência cognitiva inerente aos seres humanos, que os indivíduos representam e expressam seus conhecimentos de vida, assim como adquirem, processam, produzem e transmitem suas experiências.

Tendo em vista um termo com significado amplo, torna-se necessário delimitá-lo, para não desviarmos o nosso foco da discussão a que nos propomos. Por isso consideraremos aqui, de forma específica, a linguagem verbal. Ela é uma atividade de interação social, ou seja, dá-se em conjunto. Como também nos confirma Antunes (2014), a linguagem é "uma ação conjunta, resultado de uma troca de saberes, de informação, de propósitos e de mútuas influências, [...] em situação de conversação e de outras trocas imediatas face a face [...]. Nada é, pois, mais coletivo que a atividade da linguagem" (p. 19, grifo da autora).

Dessa forma, sendo a linguagem uma interação social, a língua também se configura como uma ação interativa, que acontece em determinado contexto social, "em que duas ou mais pessoas, reciprocamente, se empenham por cumprir algum propósito comunicativo" (ANTUNES, 2014, p. 23). Por isso, "não tem sentido reduzir as condições de sucesso das atividades de linguagem ao cumprimento de um conjunto de regras gramaticais, definidas, quase sempre, sem atenção ao que, de fato, se fala e se escreve em um particular momento histórico" (ANTUNES, 2014, p. 22).

Nessa sequência, para compreendermos uma variedade linguística precisamos delimitar suas fronteiras. Uma comunidade de fala ou comunidade linguística, conforme Labov (2008 [1972]), constitui-se das "atitudes e valores compartilhados acerca de formas linguísticas e do uso da língua” (p. 53). Dessa compreensão podemos pensar a comunidade de fala como um agrupamento de pessoas que "compartilha um conjunto de atitudes sociais para com a língua: as mesmas normas" (p.53), embora nem sempre fale utilizando as mesmas formas.

Segundo Monteiro (2000), definir uma comunidade de fala é também complexo, pois "além de não ser fácil estabelecer os limites geográficos ou sociais de uma comunidade, os linguistas não são unânimes quanto aos critérios de demarcação" (p. 39). Embora a concepção de comunidade no modelo laboviano não seja amplamente aceita, conforme afirma Monteiro (2000), utilizaremos o conceito de Labov (2008 [1972]) que surgiu a partir de análises de grupos de indivíduos, considerando-se os aspectos sociais que interferem em sua fala. De acordo com as observações de Monteiro (2000) acerca das diferentes e divergentes tentativas de vários teóricos em pontuar o que seja uma comunidade de fala, podemos afirmar que não há uma dimensão exata ou ideal para essa comunidade, podendo ser delimitada por pequenos núcleos territoriais, talvez por um município, uma cidade, um estado, ou por um país, ou até mesmo por áreas supranacionais. Portanto, esse grupo pode ser uma nação inteira ou apenas membros de uma instituição formal, como a escola.

Esses conceitos são importantes para que possamos pensar o ensino como um processo que deve considerar o aluno como um usuário ativo da língua, dotado de um saber linguístico característico de sua comunidade de fala, que pode não ser um saber próximo ao proposto pela escola, mas é igualmente legítimo.

Para que o ensino de língua seja de qualidade, ele precisa ser organizado de forma a atender democraticamente a todos os alunos. E como se estruturaria de forma justa esse ensino? Acreditamos ser necessário que haja uma recepção positiva da variação linguística 


\section{$=\mathrm{T} R A M A=$}

na sala de aula. Pois, considerando-se a natureza interativa e social da linguagem, a língua não deve ser abordada, no ensino, como uma estrutura abstrata, desvinculada do que está em uso pelo aluno.

Conforme sabemos pela teoria variacionista laboviana, existem diferentes tipos de variantes, aqui ressaltaremos as variantes de prestígio e as variantes estigmatizadoras. $\mathrm{O}$ que faz com que uma variante se torne prestigiada é o fato de ela ser "associada a um falante ou grupo social de status considerado elevado" (MONTEIRO, 2000, p. 64). Assim, em consonância com as observações de Labov (2008 [1972]), a variante das classes dominadas tende a se desestruturar, em relação à variante da classe dominante. Isso gera, infelizmente, "inúmeros sentimentos de culpabilidade ou de inferioridade linguística, que levam muitos falantes a se envergonharem de seus dialetos" (MONTEIRO, 2000, p. 64).

Com relação às variantes estigmatizadas, entendemos com Monteiro (2000) que dentre os preconceitos inerentes a uma sociedade de classes, o que se estabelece pelos usos da linguagem é o mais intenso. A depender da escolaridade, da posição social, da comunidade de fala etc., um falante pode ser rechaçado ou aceito, porque a fala de maior prestígio pertence à classe dos privilegiados.

Monteiro (2000, p. 65), em sua leitura de Labov (1972), diz-nos que "o preconceito é tanto mais forte quanto maior for a identificação da forma com a classe discriminada. À proporção que passa a ser usada por outros grupos, o estigma vai diminuindo até deixar de existir". Esse fenômeno acontece quando a variante é aceita pela classe dominante. Essa afirmação remete-nos ao pensamento do sociólogo francês Bourdieu (2007 [1979]), quando ele nos apresenta a linguagem humana como um dos principais marcadores da distinção social, considerando uma sociedade de classes como a nossa. É muito importante essa observação quando se pensam os problemas do ensino formal de língua. Será que a escola tem contribuído para reduzir a distância entre as classes? Um importante questionamento a que pretendemos responder logo adiante.

\section{A VARIAÇÃO LINGUÍSTICA NOS ENSINOS FUNDAMENTAL E MÉDIO: ACHADOS DA PESQUISA}

O quadro a seguir apresenta uma síntese do que observamos, acerca da teoria e da prática dos professores de Língua Portuguesa, durante nossas observações nas quatro turmas de educação básica (duas de ensino fundamental e duas de ensino médio) de escolas públicas e particular, no município de Mariana. A ilustração abaixo apresenta também a proposta dos PCN e CBC ao ensino de Língua Portuguesa:

Quadro 1 - teoria x prática - elaborado pelas autoras a partir da análise dos dados construídos.

\begin{tabular}{|c|c|c|c|}
\hline ENSINO & EIXO DE ENSINO & $\begin{array}{c}\text { ESTRATÉGIA DE } \\
\text { ENSINO }\end{array}$ & $\begin{array}{l}\text { HABILIDADE } \\
\text { ESPERADA }\end{array}$ \\
\hline PCN | CBC & $\begin{array}{c}\text { Análise linguística: USO - } \\
\text { REFLEXÃO - USO }\end{array}$ & $\begin{array}{l}\text { Leitura/escuta, } \\
\text { produção oral e } \\
\text { escrita, comparação e } \\
\text { reescrita de textos } \\
\text { completos }\end{array}$ & $\begin{array}{lr}\text { Perceber as } & \text { diversas } \\
\text { formas } & \text { de } \\
\text { estruturação de um } \\
\text { texto e saber } \\
\text { escolher, dentre elas, } \\
\text { a que melhor } \\
\text { assegura o sentido no } \\
\text { texto }\end{array}$ \\
\hline $\begin{array}{c}\text { TEORIA - } \\
\text { Planejamento } \\
\text { de Aula }\end{array}$ & Gramática normativa (GN) & $\begin{array}{l}\text { Exposição de termos } \\
\text { para identificação e } \\
\text { classificação }\end{array}$ & $\begin{array}{l}\text { Saber identificar e } \\
\text { classificar termos da } \\
\text { GN, em fragmentos }\end{array}$ \\
\hline
\end{tabular}




\section{$=$ TRAMA $=$}

\begin{tabular}{|c|l|l|l|}
\hline & & & de textos \\
\hline PRÁTICA & Gramática normativa (GN) & $\begin{array}{l}\text { Exposição de termos } \\
\text { para identificação e e } \\
\text { classificação }\end{array}$ & $\begin{array}{l}\text { Saber identificar e } \\
\text { classificar termos da } \\
\text { GN, em fragmentos } \\
\text { de textos }\end{array}$ \\
\hline
\end{tabular}

O quadro acima mostra-nos que as professoras-alvo da pesquisa não adotam, em suas práticas, a diretriz teórico-metodológica ao ensino presente nos documentos, indicando como isso influencia nas estratégias e habilidades esperadas. Pelos documentos, o texto é objeto de reflexão sobre o funcionamento da língua, que se concretiza a partir da análise linguística. Esse caminho só é possível fora desse campo pautado pela análise de termos em frases isoladas e abstratas, em que as produções do aluno são limitadas às correções superficiais no âmbito dos aspectos gramaticais e ortográficos.

A variação apareceu em alguns Planejamentos de Aula das professoras cujas aulas observamos, mas apenas como um conteúdo isolado do todo, a ser discutido pontualmente em uma aula ou duas, no máximo, considerando um ano letivo inteiro. Porém, como é possível notarmos no quadro acima, não haveria espaço para se tratar da língua em sua diversidade nesse âmbito em que se vigora o trabalho de LP por meio de fragmentos de textos com o objetivo de que os alunos saibam classificar termos gramaticais.

Desde a LDB 5692/71, a partir da qual se instituíram mudanças no ensino de língua, modificando drasticamente a disciplina de Português para Comunicação e Expressão, os manuais passaram a ser o cerne do ensino, visando facilitar o trabalho docente. Houve, pois, a partir de então, uma transformação no perfil e no papel do professor. Conforme Bunzen e Rojo (2005, p. 80), "o livro assume para si a tarefa de estruturar as aulas, até porque, muitas vezes, ele permanece mais tempo nas escolas do que os próprios professores" que, devido à desvalorização da condição docente, atuam diversas vezes em mais de uma escola concomitantemente, não dispondo de tempo para preparar e corrigir atividades escolares. Como esses professores permanecem por pouco tempo em cada escola, são os produtores de livros didáticos que se tornam sujeitos decisivos nos processos de ensino-aprendizagem.

Como observamos, a partir da pesquisa "Esta língua vareia: uma análise da variação linguística no ensino de língua portuguesa em Mariana, MG", ainda há um excessivo apego aos manuais: livro didático (escolas públicas) e material apostilado (escolas particulares). Nesse sistema de ensino-aprendizagem em que o livro didático e a apostila são colocados como principais, ou até mesmo únicos materiais de estudo possíveis, sem abrir espaço para outras discussões que não estejam nesses materiais, o ensino, conforme pudemos compreender, ainda se mostra tradicional. Isso, de certa forma, pode limitar a realidade do aluno porque, ao manual didático é dada a faculdade de identificar a "verdade", ficando o aluno em último plano, principalmente quando se trata da esfera pública de ensino.

Com isso cabe ressaltarmos que, embora tenham se passado aproximadamente duas décadas da publicação dos PCN (1997/2000), o ensino de classes de palavras e de conteúdos gramaticais continua sendo predominante nas aulas de Língua Portuguesa, ao menos nas escolas que nos serviram como campos de pesquisa. A promulgação dos documentos regulamentadores do ensino confirmou a real necessidade de mudança no ensino. Mas, ainda hoje, isso não parece estar sendo uma tarefa fácil para o professor, porque a sua atuação segue pelo sentido contrário ao que foi proposto pelas diretrizes. Como constatamos, não existe uma apreensão, por parte da escola/professor, dos princípios presentes nesses documentos, visto que não vimos na atuação docente ou em seu Planejamento de Aula, uma consciência de ensino-aprendizagem de língua que considere a 


\section{$=$ TRAMA $=$}

formação do indivíduo apto à cidadania, contra as discriminações, emancipado política e socialmente. Um indivíduo que saiba compreender o seu lugar imediato e seja capaz de refletir sobre si mesmo e sobre a realidade do mundo e que, assim, possa se mobilizar contra as injustiças inerentes ao nosso modelo de sociedade.

A fim de concretizarmos esse pensamento, precisamos ir muito além das práticas pedagógicas tradicionais guiadas pela transmissão do conhecimento dado; já que o ensino tradicionalista mecânico é limitador; para o aluno é um desafio produzir conhecimento através dele. Sendo dessa forma, o educando apenas recebe o conhecimento, de forma passiva, muitas vezes sem espaço para questionar a verdade absoluta imposta por meio dos manuais.

Esse quadro geral possui uma lacuna que se torna ainda maior quando consideramos a sociedade de classes, que é como se configura a nossa, e o ensino nas esferas pública e privada. Isso porque, como observamos durante a pesquisa de dissertação, os ensinos público e privado têm enfoques semelhantes com relação à característica de ensinoaprendizagem de língua "fechada na gramática normativa". Esse ensino, que não considera a diversidade, parece não ser problemático com relação ao desenvolvimento, aprendizagem e emancipação do aluno da escola particular. Porque, quando observamos as aulas, notamos que, por mais complexo que seja esse modelo de educação, os alunos, tanto do ensino fundamental quanto do ensino médio particular, identificam-se com ele, já que as turmas participam das aulas; realizam as atividades, sem apresentar grandes dificuldades; os alunos são questionadores; apresentam pensamento crítico-construtivo; obtêm resultados excelentes nas avaliações escolares; constroem um conhecimento ajustado à proposta da escola. Desse modo, certamente, para além da educação básica, eles darão continuidade aos estudos, posto que a escola os capacita a isso.

Contudo, não podemos afirmar o mesmo quando nos referimos ao ensino público, uma vez que a visão que tivemos, observando de perto, foi distinta. Ainda que ambas as esferas educacionais atuem tendo por base modelo um ensino-aprendizagem normativo de língua, o público recebido é diverso, o domínio do objeto de conhecimento, pelo aluno, é diferente. Assim, na escola pública, os alunos demonstram desânimo, estranhamento e dificuldade durante as aulas de Língua Portuguesa; eles não são participativos; não expressam seus pensamentos; têm dificuldade de organizar-se no espaço da sala de aula; não questionam; se questionados, dificilmente conseguem responder de forma produtiva e organizada; apresentam baixo desempenho nas avaliações escolares. Então, essa realidade é diferente daquilo que vimos acontecer na instituição de ensino particular.

Embora o modelo de ensino seja o mesmo, considerando os conteúdos e a metodologia de ensino nas escolas tanto pública quanto particular, os alunos não são os mesmos, os recursos também não são. Então, certamente, os resultados dessa educação não serão os mesmos.

Quando estudamos a história do ensino de língua portuguesa, entendemos que a educação, em determinado momento do passado no Brasil, não foi um direito de todos, somente crianças e jovens inerentes às classes de prestígio detinham espaço na sala de aula. Depois, por questões políticas e econômicas, houve a necessidade de formar mão de obra qualificada. Por isso foi preciso "democratizar" a educação. No entanto, junto a esse processo, aconteceu a precarização do ensino. Então, como muito bem pontuam Soares (2002) e Faraco (2008), a convencionada democratização deu-se apenas no nível do espaço escolar, não no nível do ensino: quase todo mundo pode ter acesso à escola pública, mas o ensino de qualidade continuou sendo para poucos. Isso porque a escola passou a receber alunos de todos os segmentos da sociedade, mas o ensino continuou acontecendo pelos mesmos moldes de antes, isto é, inacessível às camadas socialmente desprestigiadas.

Revista Trama | Volume 16 | Número 37 | Ano 2020 | p. 84-99 | e-ISSN 1981-4674 


\section{$=$ TRAMA $=$}

Sendo assim, pudemos ver resquícios dessa história ainda nas escolas de agora, do século XXI, do ano 2017 (ano da realização da pesquisa de campo). A educação colocada como "direito de todos e dever do Estado", no artigo 205, da Constituição de 1988, parece ser, primeiramente, contra o povo, não para o povo, conforme nos confirma Soares (2002). Essa autora mostra dados que comprovam que o fracasso escolar tem sido recorrente principalmente na rede pública, onde a reprovação, a evasão, o fluxo irregular, o baixo nível de proficiência em língua portuguesa e a baixa taxa de conclusão na idade adequada, tanto no ensino fundamental quanto no ensino médio, são consideráveis e preocupantes. A nossa busca a campo permitiu-nos construir um panorama do ensino de LP que mostra indícios dessa realidade nas escolas de agora.

Quanto à esfera particular, mesmo que aos alunos seja possibilitada maior oportunidade de sucesso nos estudos e na vida, em contrapartida, a escola não promove ações e discussões que busquem a redução das discriminações e desigualdades sociais. Trata-se de uma educação que visa mais às questões materiais do que aos problemas sociais. Entendemos que a educação que possui envolvimento positivo com a diversidade como um todo, primordialmente carece de um tratamento adequado da variação linguística, pois, como já mencionamos, a língua é um dos maiores mecanismos de distinção social (BOURDIEU, 2007). Sendo assim, a mesma língua que corrobora o fracasso do ensino público, certifica o sucesso do ensino particular.

Como bem nos esclarece Soares (2002), nesse abismo entre classes, a linguagem é um fator decisivo quando pensamos o fracasso escolar. $\mathrm{O}$ uso da língua delineia as diferenças existentes entre os diferentes grupos sociais, o que contribui para os preconceitos, o silenciamento e, consequentemente, para o fracasso do aluno que não se vê representado pela escola nem pelo professor, que usa e quer que ele apreenda uma língua que não é a sua. Na maioria das vezes, esse aluno é proveniente das classes populares e encontra-se inserido na educação pública. $\mathrm{E}$, segundo a autora, as variantes linguísticas utilizadas por esse aluno são estigmatizadas escolar e socialmente.

As aulas de língua portuguesa a que observamos possibilitaram-nos entender, por meio da prática docente, que não há clareza quanto ao tratamento da variação inerente à língua. O professor não apresenta uma percepção de ensino desejada e necessária à escola que se pretende transformadora (SOARES, 2002), cuja atuação docente compreende a língua em seu dinamismo, tendo por base conceitos da sociolinguística voltada à educação (BORTONI-RICARDO, 2005). Essa escola progressista precisa partir de uma pedagogia da variação linguística, em que os professores saibam distinguir as normas curta, gramatical e culta (FARACO, 2008), para que os diversos usos possíveis da língua possam ser incorporados ao ensino.

Como a escola parece considerar mais a norma-padrão (FARACO, 2008) - aquela norma que pretende limitar os usos reais da língua - não observamos abertura para a discussão das variedades linguísticas e, sim, uma atuação docente purista, corretiva e "higienista", que denota um ensino de língua tradicionalista, cujo foco é ensinar os preceitos da gramática normativa.

No que tange à prática pedagógica, pudemos notar uma postura de "proteção" e de "correção" da língua, que se dá, segundo Faraco (2016, p. 152), pela "tentativa de uniformizar e homogeneizar o que é heterogêneo e complexo", a partir da imposição da norma-padrão, a qual o autor nem considera como uma variedade da língua, por ela não dar conta de nenhum tipo de uso.

Então, tomando como base as aulas observadas durante a pesquisa de mestrado a que estamos nos referindo, acreditamos que o tratamento que a variação receberia caso Revista Trama | Volume 16 | Número 37 | Ano 2020 | p. 84-99 | e-ISSN 1981-4674 


\section{$=$ TRAMA $=$}

fosse abordada, visto que esse tema aparece discretamente em alguns Planos de Aula analisados, não teria como fundamento a compreensão proposta pelos documentos regulamentadores do ensino (PCN; CBC) e pelas teorias (SOARES, 2002; BORTONIRICARDO, 2005; FARACO, 2008). Isso porque, nas práticas pedagógicas, a norma-padrão ou norma curta é a que percebe valor, aquela a que Faraco (2008) entende como sendo uma regra estreita, por ela não dar conta da diversidade linguística, dos fatos da língua em uso. Além disso, não verificamos reflexões sobre a língua nas práticas das professoras, que seria o tipo de exercício cognitivo que permitiria considerar as nuances de significados na linguagem.

Assim sendo podemos afirmar que a forma como tem sido o ensino de língua portuguesa, ao menos nas escolas observadas, não demonstra consciência dos professores sobre os conceitos teóricos básicos da Sociolinguística Variacionista de Labov (2008 [1972]), nem, especificamente, da Sociolinguística Educacional, como sugere Bortoni-Ricardo (2005). E, por isso, torna-se complexo, talvez impossível, pensar o tratamento adequado e desejado da variação linguística que se espera de uma escola transformadora (Soares, 2002) no cenário investigado.

Afirmamos isso compreendendo que, em uma escola que tem como critério de ensino-aprendizagem o preparo "mecânico" do aluno aos exames de seleção para o ENEM e vestibulares - foi o que constatamos - não há de ter espaço para o entendimento e abordagem didática que considera os fatores linguísticos e extralinguísticos da língua - conforme se faz necessário, pela teoria da variação linguística. Não há de ter espaço para uma pedagogia da variação (Faraco, 2008) que atue por meio de uma abordagem heterogênea da língua, compreendendo que um tratamento acolhedor da variação, que não pretende desclassificar nenhuma forma de uso da língua, pode contribuir para a redução do preconceito linguístico praticado contra falantes de variantes desprestigiadas. Não há de ter espaço para a reflexão sobre as nuances da língua, como propõem os documentos oficiais PCN e CBC. Isso pelo motivo de que nesse modelo de escola o ensino de língua é fundamentado pelas prescrições dos manuais normativos, com a finalidade de que os alunos sejam aprovados em provas do ENEM e vestibulares. Nessa escola é esperado que a diversidade seja vista, sim, porém, como um problema, uma barreira ao ensino das normas.

Com relação aos documentos que regulamentam o ensino de LP nas escolas, reconhecemos que as concepções teóricas contidas neles privilegiam a dimensão social, interacional e discursiva da língua e estabelecem que o domínio dessa língua, pelo aluno, é uma das principais condições para a sua plena participação social. Além disso, privilegiam os conteúdos de língua portuguesa em articulação nos eixos uso da língua oral e escrita e reflexão sobre esses usos. E não há nenhuma menção aos conteúdos gramaticais nas formas tradicionais das classes de palavras. Todavia, os PCN e CBC estabelecem caminhos, mas não definem os direcionamentos, além de serem restritos, porque há um distanciamento entre os documentos e a realidade educacional no nosso país. Então, não parece ser fácil para o professor trabalhar com essa discussão. Isso pode ser o principal fator de a variação ser tratada no currículo escolar, mas não ser trabalhada de fato nas aulas de LP.

"A questão não é de correção da forma, mas de sua adequação às circunstâncias de uso, ou seja, de utilização adequada da linguagem." (BRASIL, 1998, p. 16). Diante dessa afirmativa contida nos PCN, o professor, possivelmente, se questionaria: "O que eu faço, então, com o aluno que diz 'nós cheguemu'?". E, de acordo com a nossa análise feita dos documentos oficiais, podemos dizer, com segurança, que esse professor não encontraria resposta nos PCN.

Nesse sentido, Alves (2002) nos leva a pensar uma educação romântica, libertadora e crucial aos "novos tempos". Essa educação seria possivel em um cenário cujo ensino Revista Trama | Volume 16 | Número 37 | Ano 2020 | p. 84-99 | e-ISSN 1981-4674 


\title{
$=$ TRAMA $=$
}

possibilitaria ao aluno avaliar o conhecimento transmitido frente a sua realidade de vida, isto é, o educando poderia compreender o saber ensinado de forma concreta, pois seria capaz de relacionar ciência e vida. Dessa forma, o aprendiz conseguiria buscar soluções aos próprios problemas; pensar por si mesmo. Para isso, o currículo escolar deveria ser definido pela vida e pelos desafios com que o educando pode encontrar ao se relacionar com o mundo ao redor (ALVES, 2002).

Por conseguinte, Alves (2002), visando refletir o lugar do professor, a relevância dos conteúdos escolares e a qualidade no ensino, faz as seguintes perguntas retóricas:

\begin{abstract}
Será que a aprendizagem dos programas oficiais se identifica com o ideal de uma boa educação? Você sabe o que é "dígrafo"? E os usos da partícula "se"? [...] E o sujeito da frase "Ouviram do Ipiranga as margens plácidas de um povo heroico o brado retumbante"? Qual a utilidade da palavra "mesóclise"? Pobres professoras, também engaioladas... São obrigadas a ensinar o que os programas mandam, sabendo que é inútil. Isso é hábito velho das escolas (ALVES, 2002, p. 31).
\end{abstract}

O autor reitera que o saber escolar deve ter utilidade na realidade concreta, devendo abarcar o ser humano como um todo, apontando o necessário diálogo entre saber e vida como um processo libertário não somente ao educando, mas também ao professor.

A escola de que estamos falando, mais se aproxima da escola redentora e impotente de que nos fala Soares (2002), cuja atuação se faz no sentido de erradicar as "deficiências" linguísticas e promover a "aquisição" da linguagem socialmente prestigiada, fazendo com que o aluno se adapte às exigências da sociedade.

\section{A VARIAÇÃO LINGUÍSTICA NO PROCESSO ALFABETIZAÇÃO-LETRAMENTO DE CRIANÇAS}

Chevrot et al (2013) explicitam que, no domínio sociolinguístico, a aquisição da linguagem pela criança continua sendo um campo recente. No entanto, é provável que a aquisição de variáveis sociolinguísticas e suas normas de uso ocorra ao mesmo tempo em que se dá o desenvolvimento geral das habilidades linguísticas. Assim sendo, esses autores compreendem que a aquisição da variação é, pois, parte que integra a própria aquisição, não um subproduto do processo de aprendizagem.

No processo de conscientização linguística, conforme Bortoni-Ricardo (2005), o desenvolvimento da consciência fonológica é requisito essencial a qualquer método de alfabetização. Para Guedes e Gomes (2010), "consciência fonológica é a capacidade da criança de analisar a linguagem oral de acordo com as sequências de sons que a compõem. Permite a reflexão sobre os sons da fala e sua organização na formação das palavras."

Soares (2018) compreende que a consciência fonológica atua de maneira mais intensa na aprendizagem inicial de língua escrita enquanto outras consciências linguísticas, como a consciência sintática, a morfológica etc., vão se tornando fundamental após a criança ter vencido a aprendizagem inicial de codificação, decodificação, leitura e escrita de palavras. "A experiência com língua escrita aumenta a capacidade de consciência sintática (p. 145). E as regras morfológicas certamente também são aprendidas algum tempo depois de as crianças dominarem as associações básicas fonema-grafema; "assim, a aprendizagem morfológica sem dúvida ocorre depois da aprendizagem fonológica da aquisição de regras ortográficas" (SOARES, 2018, p. 156).

À vista disso, Soares (2018) chama a atenção para uma dificuldade compreendida no âmbito da pesquisa sobre consciência metassintática: a interferência da variedade linguística 


\section{$=$ TRAMA $=$}

da comunidade de fala em que a criança está inserida, que se aproxima ou se distancia em diferentes níveis da variedade considerada padrão.

A educação brasileira não dá suporte para que seus alunos acessem efetivamente à cultura letrada (BORTONI-RICARDO, 2005, 2006; FARACO, 2008; SOARES, 2002). Isso justifica o grande percentual de brasileiros analfabetos ou analfabetos funcionais, ainda que 0 número de matrículas e frequência de crianças no ensino fundamental também seja grande.

Há décadas, o Ministério da Educação aplica exames por meio do Sistema Nacional de Avaliação da Educação Básica (SAEB) a fim de avaliar, dentre outras questões, a compreensão de leitura. As médias de desempenho dos estudantes, apuradas no Saeb 2017 , mostram que o nível adequado de proficiência dos alunos em Língua Portuguesa é muito pequeno. Esses poucos alunos que alcançam nível de aprendizagem adequado, provavelmente, são aqueles que darão continuidade aos estudos, para além da educação básica. As dificuldades que a maioria apresenta com relação à leitura e escrita determina a curta trajetória escolar dos alunos. E, conforme esse teste, os alunos do ensino fundamental que apresentam níveis inadequados de proficiência em LP são, geralmente, aqueles cuja cultura familiar se encontra mais distante da cultura escolar (letrada), isto é, a maior parte das crianças que não alcançam o resultado desejado no Saeb são oriundas de classes populares. E isso nos diz muito acerca da variação linguística no processo alfabetização-letramento.

O analfabetismo é um problema persistente no Brasil e acreditamos que uma das carências educacionais que contribui para esse fato são os métodos caóticos adotados por professores despreparados. Alguns pesquisadores da área de Ciências Humanas, principalmente na Linguística, têm realizados estudos a fim de contribuírem para a resolução desse problema no Brasil (BARBOSA, 1981; BORTONI-RICARDO, 2005; FARACO, 1992, 2008; SOARES, 2018; dentre outros). Esses estudiosos se preocupam por compreender e explicitar o ensino-aprendizagem de leitura e escrita no processo inicial de aprendizagem escolar (alfabetização). Por se tratar de um problema extenso, que envolve muitas questões, mesmo com grandes estudos aplicados sobre o tema, ainda não temos resultados relevantes na prática, isto é, ainda há muito a ser feito.

Soares (2018) argumenta que, na alfabetização, o principal aspecto a ser alcançado pela criança é o reconhecimento de palavras, esse fenômeno é o que vai fazer com que o aluno compreenda o princípio alfabético: saiba relacionar, de forma consciente, fonemas (sons) e grafemas (letras). Para isso, a fonologia é o ramo da linguística que pode contribuir para que a criança consiga fazer esse reconhecimento, traduzindo sons em letras e letras em sons, ou seja, seja capaz de ler e de escrever. No entanto, não se trata de um processo simples; desenvolver a consciência fonológica ou adquirir a habilidade de compreender que as palavras possuem sons distintos, podendo ser repartidas em sílabas e em fonemas envolve uma complexidade de mecanismos que o alfabetizando precisa acionar.

Nesse sentido, o professor alfabetizador precisa ter um olhar sob a perspectiva sociolinguística, ao trabalhar o princípio alfabético, sabendo sobre a relação fala-escrita, para que a criança adquira a consciência fonológica sem "ruídos", ou seja, sem deixar dificuldades que a acompanharão por toda a sua vida. Essa relação fala-escrita deve ser trabalha sistematicamente nos primeiros contatos com a língua escrita.

De acordo com Soares (2018) essa forma de ensino-aprendizagem na alfabetização tem por base o método fônico, mas não se trata de velhos modelos comportamentalistas que pautavam-se em uma prática pedagógica de estímulos e respostas, ou de fragmentação de palavras em sílabas para os alfabetizandos recitarem-nas sequencialmente, mecanicamente e de forma descontextualizada. A autora defende o método fônico, mas nos leva a ponderar que não se deve enfocar a decifração exaustiva de palavras, já que isso não contribui à 


\section{$=$ TRAMA $=$}

aprendizagem da criança. O método fônico é relevante na medida em que se configura em um ensino que se relaciona de forma significativa com as experiências do aprendiz, ou seja, a aprendizagem pelo sistema fônico se efetiva quando acontece de forma contextualizada, representando a cultura da criança.

Bortoni-Ricardo (2005), nessa mesma linha de pensamento, compreende que leitura, escrita e fala são fenômenos que se associam, assim propiciar ao aluno o desenvolvimento da consciência fonológica é muito importante para que ele compreenda o princípio alfabético, que subjaz à ortografia. Mas isso não significa retomar antigas práticas de ensino de fragmentos de palavras fora de contextualização. Bortoni-Ricardo argumenta a favor da relevância do contexto na alfabetização-letramento; o ensino significativo é aquele que desperta o interesse, garantindo a verdadeira aprendizagem.

Conforme colocamos na introdução deste artigo, é preciso, então, pensar o papel da escola e do professor nesse campo onde o processo ensino-aprendizagem deveria acontecer partindo-se da premissa de que alfabetização e letramento são uma unidade cujo aluno, sua cultura, sua oralidade são o centro para a construção do trabalho com a linguagem; o aprendiz não é uma folha de papel em branco a ser preenchida pela escola/professor e o que fornece subsídios para a sua aprendizagem é justamente a ferramenta cultural mais forte que ele traz consigo, sua maneira de se comunicar e de apreender o mundo, aspectos que fazem parte do seu universo cultural. As crianças inseridas no ensino fundamental I, principalmente, aquelas em processo de alfabetização são falantes competentes da nossa língua portuguesa brasileira, mas fazem uso da variedade de língua da sua comunidade linguística que pode ser muito próxima ou muito distante da variedade de uso, de ensino e de transmissão da cultura letrada pela escola.

Se no processo de alfabetização das crianças o professor não tiver como base de trabalho o saber que seu aluno possui ao chegar à escola, não será possível a todos acessarem a cultura letrada, consequentemente, dificilmente conseguiremos erradicar o analfabetismo no Brasil. A cultura da oralidade, que abrange a diversidade linguística e as muitas possibilidades de aprendizagem é aspecto decisivo na alfabetização.

Todavia, vimos com Bortoni-Ricardo (2005) e Soares (2018) que a alfabetização no Brasil possui diversas lacunas. Um dos grandes problemas que podemos mencionar é o fato de que, como estamos discutindo, o desenvolvimento da consciência fonológica tem de estar na base de reflexão dos métodos de alfabetização, já que a aquisição dessa consciência é que vai permitir ao educando adquirir o princípio alfabético e, posteriormente, dominar o sistema ortográfico. No entanto, existe uma contradição na formação de professores no nosso país: são nos cursos de Letras que professores apreendem o funcionamento do sistema fonológico da língua portuguesa, mas não é prática comum desses profissionais formados em Letras atuar na alfabetização, além disso, os currículos desse curso voltam-se para a formação de professores para atuarem no ensino fundamental II e no ensino médio. Assim, os professores alfabetizadores se formam nos cursos de Pedagogia, cujos currículos não acrescentam disciplinas de Linguística que possibilitem a esses profissionais habilidades para atuarem tendo eles próprios consciência linguística e/ou fonológica. A saber, "a consciência linguística ou metalinguística refere-se à habilidade de refletir sobre a língua, isto é, de tratar a língua como objeto de análise e observação, de focalizar a atenção especificamente para as suas formas" (GUEDES; GOMES, 2010).

Mattoso Câmara Jr. (1977) observou que é importante que a variação fonológica seja inserida no universo dos alfabetizadores, já que muitas dificuldades que os alunos demonstram com relação às atividades de leitura e de escrita se relacionam a essa variável. É crucial o trabalho com regras variáveis também nas séries iniciais no que tangem propostas 


\section{$=$ TRAMA $=$}

de leitura e de escrita e o campo de estudos da sociolinguística é de extrema importância para que professores e alunos possam perceber a variação linguística como um fenômeno natural e importante na língua.

Portanto, a aprendizagem inicial da língua escrita é composta por facetas (SOARES, 2018), cabe ao professor alfabetizador dominá-las no âmbito do ensino-aprendizagem, porque sendo assim, tornar-se-ia uma possibilidade trabalhar com a diversidade em sala de aula. Isso porque, a faceta linguística propicia o conhecimento do sistema alfabético-ortográfico de escrita; a faceta interativa enfoca o uso da língua escrita para interação: compreensão, produção de textos; e a faceta sociocultural prevê os usos e as funções da língua escrita em diferentes contextos sociais e culturais. A faceta linguística da aprendizagem inicial focaliza a conversão da cadeia sonora da fala em escrita. Sendo assim, a dimensão linguística é predominante no processo de aprendizagem inicial da escrita. Segundo Perfetti (2003 citado por Soares, 2018), aprende-se, durante a escrita, muito mais do que a codificação, mas é nesse evento de aprendizagem central que devem ser associadas aprendizagens adicionais de letramento.

Neste artigo, quanto à alfabetização, o teor é de reflexão acerca de como escola e professores podem operar no sentido de usar adequadamente a cultura do aluno em prol de sua aprendizagem. Como o professor poderia planejar seu trabalho a partir da competência linguística apresentada pela criança, visando tornar a aquisição da escrita um processo significativo e eficaz ao aprendiz? Não temos uma resposta pronta, mas podemos seguir modificando as antigas práticas e nos apegando ao novo, experimentando as novas propostas que estão emergindo e adequando-as à realidade dos sujeitos e dos espaços possíveis.

\section{CONSIDERAÇÕES FINAIS}

A realização da pesquisa de mestrado nos possibilitou compreender algumas contradições no ensino de língua e a forma como isso impacta na qualidade da aprendizagem. Há contradição, principalmente, na relação entre a percepção do ensino de Língua Portuguesa postulada pelos documentos oficiais ( $\mathrm{PCN}$ e $\mathrm{CBC}$ ) e teoria e prática de professoras no que concerne à variação linguística nesse processo. Isso contribui para o silenciamento de alunos de escolas públicas à proporção que contribui para legitimar o conhecimento de alunos de escola particular.

Com relação à variação linguística no processo alfabetização-letramento (anos iniciais), refletimos acerca de alguns conceitos linguísticos que podem contribuir no processo inicial de aprendizagem da língua escrita pela criança, bem como sobre (im)possibilidades à desconstrução de preconceitos e de velhas práticas. Assim, argumentamos que o caminho a ser seguido pode ser construído a partir da valorização dos saberes dos alunos. Para isso, vimos que é primordial que professores alfabetizadores atuem sob a perspectiva da sociolinguística educacional, considerando a diversidade linguística como fenômeno importante à aprendizagem. Conhecer a realidade linguística dos alfabetizandos é essencial, porque dessa maneira tornar-se-ia possivel realizar um trabalho que pretende despertar a consciência linguística dos alunos, especificamente, a consciência fonológica, que é o ponto de partida para todas as demais especificidades da língua.

Em vista disso, "não podemos escapar de dizer que é inevitável e indispensável que se encontrem os meios para alterar profundamente as relações entre teóricos, elaboradores de diretrizes e docentes da educação básica" (FARACO, 2008, p. 194). Acreditamos, com base nisso, que o professor deveria assumir um papel de protagonista das mudanças no ensino. Mas, para além disso, segundo Faraco (2008), e com o qual concordamos, é preciso rediscutir a formação docente, garantindo-lhes o domínio necessário das práticas de língua 


\section{$=$ TRAMA $=$}

oral e escrita. E também investir em formação continuada, melhoria de salário e de condições de trabalho docente. $E$, ainda, combater preconceitos, estigmas e violência simbólica praticados contra o modo como se fala (e, de certa forma, como se escreve). É urgente, ainda, segundo esse mesmo autor, haver uma reavaliação das políticas públicas das últimas décadas cujos programas e orientações criados não alcançaram a sala de aula.

Portanto, um ensino de língua que se quer democrático, que assegura a todos os alunos um conhecimento ampliado e diverso da língua, pela perspectiva de um tratamento adequado dos fenômenos de variação em sala de aula, deve estimular uma reflexão e análise que abarquem todas as variedades sociolinguísticas, "para que o espaço da sala de aula deixe de ser o local para o estudo exclusivo das variedades de maior prestígio social e se transforme num laboratório vivo de pesquisa do idioma em sua multiplicidade de formas e usos" (BAGNO, 2007, p. 32).

\section{REFERÊNCIAS}

ALVES, R. Por uma educação romântica. São Paulo: Papirus, 2002.

ANTUNES, I. Gramática contextualizada: limpando "o pó das ideias simples". São Paulo: Parábola Editorial, 2014.

BAGNO, M. Nada na língua é por acaso - por uma pedagogia da variação linguística. São Paulo: Parábola, 2007.

Dicionário Crítico de sociolinguística. São Paulo: Parábola Editorial, 2017.

BARBOSA DA SILVA, Mírian. Leitura, ortografia e fonologia. São Paulo: Ática, 1981.

BORTONI-RICARDO, S. M. Nós chegemu na escola, e agora? Sociolingüística e educação. São Paulo: Parábola Editorial, 2005.

BOURDIEU, P. A distinção: crítica social do julgamento. São Paulo: Edusp; Porto Alegre, RS: Zouk, 2007.

BRASIL, Secretaria de Educação Básica. Parâmetros Curriculares Nacionais (PCN): Terceiro e Quarto ciclos:

Língua Portuguesa. Brasília: MEC/SEF, 1998, 106 p. Disponível em: <http://portal.mec.gov.br/seb/arquivos/pdf/portugues.pdf>, Acesso em: 15 jun. 2018.

BUNZEN, C.; ROJO, R.. Livro didático de língua portuguesa como gênero do discurso: autoria e estilo. In: COSTA VAL, M. da G; MARCUSCHI, Beth (Orgs.). Livros didáticos de língua portuguesa: letramento, inclusão e cidadania. Belo Horizonte: Ceale; Autêntica, 2005.

CÂMARA JÚNIOR, Joaquim Mattoso. Para o estudo da fonêmica portuguesa. Rio de Janeiro: Padrão, 1977.

CHEVROT, J. P.; NARDY, A.; BARBU, S. The acquisition of linguistic variation: looking back and thinking ahead. De Gruyter Mouton, 2013.

FARACO. C. A. Norma culta brasileira: desatando alguns nós. São Paulo: Parábola Editorial, 2008.

História sociopolítica da língua portuguesa. São Paulo: Parábola Editorial, 2016.

Escrita e alfabetização: características do sistema gráfico do português. São Paulo: Contexto, 1992.

GIL, A. C. Como elaborar projetos e pesquisa. 3a ed. São Paulo: Atlas, 1995.

GUEDES, M. C. R.; GOMES, C. A. Consciência fonológica em períodos pré e pós-alfabetização. Cadernos de Letras da UFF - Dossiê Letras e Cognição 2010; 41: 263-281.

LABOV, W. Padrões Sociolinguísticos. São Paulo: Parábola, 2008 [1972].

LÜDKE, M; ANDRÉ, M. E. D. A. Pesquisa em educação: abordagens qualitativas. São Paulo: EPU, 1986.

MINAS GERAIS. Secretaria de Estado de Educação de Minas Gerais. Proposta Curricular: Conteúdo Básico Comum - Língua Portuguesa: ensinos fundamental e médio. Minas Gerais, 2007. Disponível em: <file:///C:/Users/Viviane/Downloads/CBCEFM\%20portugu\%C3\%AAs\%20(1).pdf>, acesso em: 27 ago. 2018. MOLLICA, M. C. Fundamentação teórica: conceituação e delimitação. In: MOLLICA, M. C., BRAGA, L. M. (orgs.). Introdução à Sociolinguística: o tratamento da variação. São Paulo: Contexto, 2003.

MONTEIRO, J. L. Para compreender Labov. Petrópolis, RJ: Vozes, 2000.

ORLANDI, E. P. As formas do silêncio. No movimento dos sentidos. 4. ed. São Paulo: Editora da Unicamp, 2007.

SOARES-SENA, V. A. Esta língua "vareia": uma análise da variação linguística no ensino de língua portuguesa em Mariana, MG. 115 f. Dissertação (Mestrado em Letras) - Instituto de Ciências Humanas e Sociais, Universidade Federal de Ouro Preto, Mariana, 2018.

SOARES, M. Linguagem e escola: uma perspectiva social. 17a ed. São Paulo: Ática, 2002.

Alfabetização: a questão dos métodos. São Paulo: Contexto, 2018.

YIN, R. Estudo de Caso: planejamento e métodos. Porto Alegre: Bookman, 2005. 